\title{
The Burden of Fatigue in Cancer Patients
}

\author{
Eduardo Bruera \\ Department of Palliative Care and Rehabilitation Medicine, The University of Texas M. D. Anderson Cancer Center, Houston, TX, USA
}

In this issue of the journal Dr. Kuhnt, et al. [1] publish an important study on the frequency and correlates of fatigue among cancer survivors. The authors approached an excellent representative sample of patients who had completed primary cancer treatment between 2 and 2.5 years before and they used a number of validated questionnaires to determine the frequency, severity, and possible predictors for fatigue. $36 \%$ of the patients had moderate fatigue, defined as the seventy-fifth percentile in the sample, and $12 \%$ of the patients had severe fatigue, defined as the ninetieth percentile. General fatigue and most of the sub-types of fatigue were strongly associated with the presence of depression. Sleep difficulties, pain, anxiety, and adjustment to illness were also significantly associated with general fatigue and the different sub-types of this syndrome. It is of interest that most demographic characteristics such as sex, age, or type of previous cancer treatment were not significantly associated with the intensity of fatigue. Unfortunately, less than $50 \%$ of the variance can be explained by all the variables measured by the investigators.

This study is important because it confirms in a large and reproducible patient population that fatigue continues to be a major problem among cancer patients several years after having completed their treatment. The findings of this study suggest that fatigue among survivors is associated with a number of major psychosocial symptoms. In this sense fatigue in these patients resembles more the type of fatigue seen in the internal medicine population as compared to fatigue among patients with advanced cancer, in whom there appears to be a stronger association with physical symptoms such as pain, nausea, anorexia, and overall performance status [2].

The findings from this study and others $[3,4]$ confirm that fatigue among cancer survivors is a complex, multidimensional syndrome that is likely to result from chronic effects of pro-inflammatory cytokines and tumor by-products, longterm side effects of antineoplastic treatments, mood changes, loss of lean body mass, physical and mental de-conditioning, and long-term metabolic and endocrine abnormalities [5]. The measurement of fatigue is always a challenge. It is not possible to measure the production of fatigue since there is no strong correlation with any particular laboratory marker or physical finding. It is also impossible to measure the amount of perception of this syndrome at the somato-sensory brain cortex. Therefore, as it is in the case of most cancer related symptoms what we measure is the patient's expression and this is not only influenced by the variation in production and perception of fatigue but also by variation in the patient's mood, beliefs about the causes of fatigue, and a number of family and cultural influences.

Where do we go from here? Since most of the variance in fatigue in both cancer survivors and advanced cancer patients is unexplained, our research efforts need to focus on the identification of circulating tumor- or host-related factors, autonomic failure, endocrine abnormalities (particularly testosterone, cortisol, or thyroid hormones), and more sophisticated measurements of body composition, physical deconditioning, and subtle cognitive changes.

In the meantime, the current emerging knowledge on cancer fatigue is that this is a multicausal syndrome that is unlikely to respond to any single intervention. Clinical trials on the management of fatigue need to focus on multiple interventions aimed at decreasing inflammation, enhancing mood and central nervous system stimulation, exercise, identification and management of metabolic and endocrine abnormalities, and patient counseling and education regarding the readjustment of living and working life to a different reality. Early and aggressive management of pain can prevent unnecessary suffering and chronic plasticity changes that might result in the development of chronic pain syndromes. An important question is if regular screening and early and aggressive management of fatigue is also capable of preventing the development of these devastating complications when patients achieve survivor status.

\section{KARGER}

Fax +497614520714

Information@Karger.de

www.karger.com (c) 2009 S. Karger GmbH, Freiburg

Accessible online at:

www.karger.com/onk
Eduardo Bruera, M.D.

Department of Palliative Care and Rehabilitation Medicin

The University of Texas M. D. Anderson Cancer Center

1515 Holcombe Blvd., Houston, TX 77030, USA

Tel. +1 713-745 7003, Fax -792 6092

ebruera@mdanderson.org 


\section{References}

1 Kuhnt S, Ernst J, Singer S, Rüffer JU, Kortmann RD, Stolzenburg JU, Schwarz R: Fatigue in cancer survivors - prevalence and correlates. Onkologie 2009; 32: DOI: $10.1159 / 000215943$.

2 Yennurajalingam S, Palmer JL, Zhang T, Poulter V, Bruera E: Association between fatigue and other cancer-related symptoms in patients with advanced cancer. Support Care Cancer 2008;16:1125-1130.

3 Loge HH: Assessment of fatigue in palliative care; in Bruera E, Higginson IJ, Ripamonti C, von Gunten CF (eds): Textbook of Palliative Medicine. Hodder Arnold, London, 2006, pp 621-628.

4 Courneya KS, Vallance JKH, McNeely ML, Peddle CJ: Exercise, physical function, and fatigue in palliative care; in Bruera E, Higginson IJ, Ripamonti C, von Gunten CF (eds): Textbook of Palliative Medicine. Hodder Arnold, London, 2006, pp 629-638.

5 Gamondi C, Neuenschwander H: Pathophysiology of fatigue; in Bruera E, Higginson IJ, Ripamonti C, von Gunten CF (eds): Textbook of Palliative Medicine. Hodder Arnold, London, 2006, pp 613-620. 